\title{
A Study of Cultural Education Infiltration in College English Teaching
}

\author{
Wei Qing \\ School of Foreign Studies, Xi'an University, Shaanxi, China, 710065
}

Keywords: College English teaching; cultural education; infiltration

\begin{abstract}
College English is one of the components of quality education. With the deepening of College English reform, the application of cross-cultural awareness in language teaching has been widely recognized by teachers and students. Through cross-cultural education, students not only master the English language, but also understand the essence of foreign culture, which is more conducive to improving the cultural literacy of college students, and is of great significance in promoting international exchanges and adapting to the development of global integration. The process of learning a language should also be the process of learning its language and culture. College English teaching should combine language teaching with social and cultural knowledge teaching. Therefore, College English teachers should strengthen the cultural education of students in combination with textbooks, and infiltrate cultural education into all aspects of classroom teaching.
\end{abstract}

Nowadays, with the increasing trend of globalization and the increasing communication between different countries and nationalities, modern people must have a certain level of intercultural language communication. It is also one of the main goals of foreign language teaching in Colleges and universities to enable students to become modern talents with strong intercultural communicative competence. The newly revised College English Teaching Syllabus in 2012 clearly stipulates that the cultivation of intercultural communicative competence must be strengthened in College English teaching.

\section{The Importance of Cultural Infiltration}

Firstly, the characteristics of language itself and the relationship between language and culture determine that cultural infiltration should be carried out in College English teaching. "Language and culture are closely linked," said Ms. Fao Ding. "Without understanding the history and culture of English-speaking countries, even if you can speak English, misunderstandings and other difficulties will inevitably arise in communication." Therefore, it is necessary for us to infiltrate the target language culture while carrying out language teaching.

Secondly, English culture teaching is an important part of College English teaching. College English syllabus (revised edition) also clearly requires that college English teaching should "train students to communicate information in English" and "help students master good language learning methods and improve cultural literacy". These are all related to culture. College is an important 
stage for a person to improve his English cultural accomplishment, so it is necessary for us to give students a good cultural teaching in college.

Finally, cultural infiltration can stimulate uninteresting in learning and meet their language learning requirements, thus promoting college English teaching and exerting a positive impact on language learning. College English texts are rich in materials, covering the history, geography, society, humanities, value orientation and social concepts of English-speaking countries. If English teachers can introduce relevant cultural background knowledge to students while explaining the text, they can not only stimulate uninteresting in learning, but also help students better understand the text and deepen their impression, so that students can understand the target language more comprehensively and accurately.

\section{The Current Situation of Cultural Infiltration in College English Teaching}

In foreign language teaching, social and cultural factors have always been neglected, because English teaching in China mainly caters to examination-oriented education, and generally pays more attention to written examination results. Traditional linguistic teaching and structuralist linguistics also generally believe that the object of linguistic research is language itself $(\mathrm{H}$ Zhengzhou, 2011). As a result, teachers pay special attention to the knowledge points involved in CET-4 and CET-6 in teaching.

On the other hand, in teaching, students only pay attention to what the teacher teaches, learning methods are rigid and lack the initiative to learn. They will not make full use of their spare time to read books on the cultural background of Britain and the United States. Therefore, telecommunications competence has never been fully explored. For example, students often use the Chinese way of thinking to express, so often misunderstood, so that both sides of the exchange feel that Hen an to understand each other, lost interest in each other. Therefore, giving enough attention to cultural teaching should be put on the agenda.

\section{Contents of Cultural Infiltration}

Culture is a very complex phenomenon and has a wide range of concepts. As far as English teaching is concerned, it refers to the brief introduction of the author's life involved in the text, as well as the local customs and customs, the national system and the origin of some specialized institutions involved in some words in the article. There is even something about literature and art. Therefore, in the process of College English teaching, the emphasis is generally laid on the following aspects: the cultural knowledge implied in vocabulary, the background knowledge of the author's life, the cultural background involved in the text and some cultural content beyond the language. As shown in figure 1

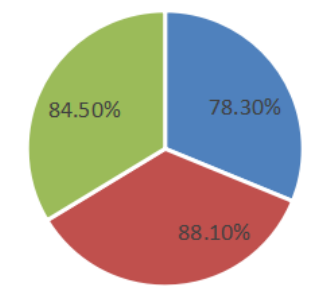

- Let students understand the cultural knowledge contained in vocabulary

- Fully Analyzing the Cultural Information of Text

- Teaching Cultural Knowledge Beyond Language

Figure 1.Contents of Cultural Infiltration 


\subsection{Let Students Understand the Cultural Knowledge Contained in Vocabulary}

In vocabulary teaching and learning, the cultural knowledge contained in vocabulary is difficult. These cultures include the scope of pronouncing words, associative meanings and emotional colors. Daily dialogues involve the standardized use of communicative terms and etiquette and customs. Students are most likely to use words improperly, because when choosing language forms, we always feel confused because we do not understand some cultural connotations, which shows the importance of explaining the cultural background knowledge of vocabulary. Some words are very simple in form. For students, although pronunciation and spelling are not a problem, they still can not understand the meaning of the whole sentence because of the cultural meaning contained in the vocabulary itself.

\subsection{Fully Analyzing the Culltural Information of Text}

Most of the college English learning materials are in the form of discourse, and each text is full of cultural information. Words, idioms and other fixed structures sometimes need to dig out the cultural information behind them. Words, idioms and other fixed structures sometimes need to dig out the cultural information behind them in order to make denuclearizing enlightened and improve their enthusiasm for English learning.

For example, in English, footmen: one5 Waterloo means fatal defeat, reflecting Napoleon's decisive defeat in Waterloo in 1815, which changed the whole situation. Dun expects $\mathrm{K}$ to be back in a hurry and the situation is difficult. In conveying discourse information, it is very important to improve enthusiastically for English learning through cultural guidance. For example, in English, "downpour:" means "complete failure". The source of this phrase is down when a fighter was knocked down in the ancient Roman arena. If he could not stand up within a specified time, it is called out. It means complete failure. After explaining it to the students, they seem to have a sudden insight and are able to use it with ease.

\subsection{Teaching Cultural Knowledge beyond Language}

There are various body languages in English. Gestures are also a part of body language, which can be understood in different countries and cultures. I once read such a story in a magazine. A Chinese arrived in the long-awaited United States by air because of too much luggage and the need for a truck to carry luggage. He asked an American if there was such a convenient service at the airport. The American used a gesture that he thought was very simple and common. Everyone understood it as "A-OK" (yes, or free). As a result, the Chinese was unfamiliar with the cultural background of the gesture. Applying the Chinese cultural background, he understood the meaning of "charging a lot of money", so he took up his luggage with great dissatisfaction and left. The American was also very puzzled. Obviously, we must respect the customs and habits of different countries, otherwise it will cause serious consequences.

\section{Teaching Strategies of Cultural Infiltration}

Language and culture are interdependent and inseparable. College English teaching is not only language teaching, but also culture teaching. The infiltration of relevant linguistic and cultural background knowledge in language teaching and the presentation of the unique social features of English-speaking countries can enhance hypersensitivity to cultural differences and stimulate students' interest in learning. Therefore, College English teachers can try to strengthen the infiltration of agriculturalist knowledge from the following aspects. As shown in Table 2: 


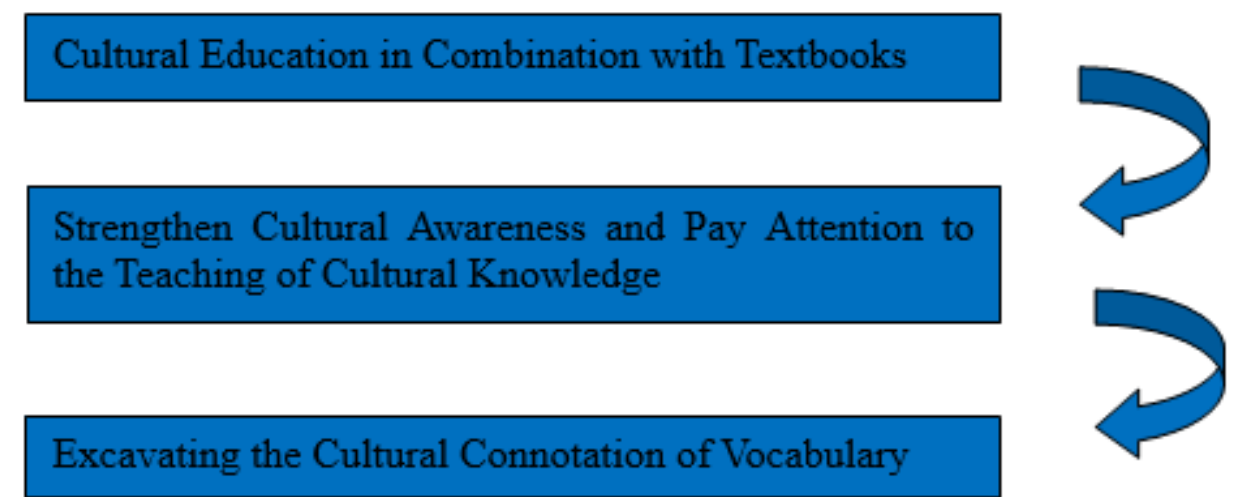

Figure 2.Teaching Strategies of Cultural Infiltration

\subsection{Cultural Education in Combination with Textbooks}

College English syllabus clearly points out that college English teaching should help students broaden their horizons, broaden their knowledge, deepen their understanding of the world, learn from and absorb the essence of foreign culture, and improve their cultural literacy. Culture and language are closely related. Certain cultural background knowledge can help to improve the ability of language application. Make full use of College English textbooks for cultural education. In many texts, language and culture are integrated to form an organic whole, which can be used not only for learning English language, but also for introducing British and American culture. Teachers should not only pay attention to the explanation of vocabulary and grammar, but also to the analysis of cultural factors when teaching texts.

For example, when designing questions for students to answer according to the content of the text, cultural follow-up is needed to let students think about why the situation is like this in the text, and what will happen when similar things happen in China. In order to guide students to compare cultural differences. So as long as we keep the idea of culture teaching in our minds and make full use of these materials, we can not only impart language knowledge, but also cultural knowledge, and cultivate studentship and cultural ability.

\subsection{Strengthen Cultural Awareness and Pay Attention to the Teaching of Cullural Knowledge}

In English teaching, there are many ways to teach culture. Teachers should adopt flexible and changeable methods to improve agriculturalist sensitivity and cultivate cultural awareness so that they can integrate into the new cultural environment independently and consciously. To strengthen the comparison between Chinese and Western cultures, we should naturally integrate the differences between Chinese and Western cultures in various aspects of daily life, conversation topics and values into English teaching, and adopt channelization, channelization and multi-access to absorb and experience foreign cultures. Using audio-visual materials, English original newspapers, magazines, foreign websites and so on, students can develop good habits of self-learning, and the study of British and American culture runs through all aspects of learning and life.

\subsection{Excavating the Cultural Connotation of Vocabulary}

In the symbolic system of language, vocabulary is one of the most prominent aspects influenced by culture. Teachers should focus on the cultural connotation of vocabulary. In vocabulary teaching, when some connotations are different or contrary, the two cultures can be compared, so that students can learn vocabulary at the same time contact with the relevant culture. For example, the 
word "west wind" refers to the harsh winter wind for the Chinese, while the British associate it with warm and warm winds. Because Britain is an island country, affected by the North Atlantic Warm Current, the wind from the west is always warm. Shelley, an English poet, wrote the famous Ode to the West Wind. If we don't understand this difference, it's very difficult to understand the poet's feelings.

\section{Conclusion}

In such a non-English environment as China, it is impossible to acquire systematic knowledge of British and American culture in only a few books in a few years. Especially for college English teachers, there are many difficulties, because there are many contents and few class hours.

\section{References}

[1] Department of Higher Education, Ministry of Education. Requirements for College English Teaching. Shanghai Foreign Language Education Press, 2012.2

[2] H Zhengzhou. Thoughts on China's Foreign Language Education Planning. Foreign Language Teaching and Research. 2011, (1): 13011363

[3] H Zhengzhou. Introduction to intercultural communication. Beijing: Foreign Language Teaching and Research Press, 1999.4

[4] Li Rung. English Teaching in the 21st Century A British Survey. Foreign Language Teaching and Research, 1996.5

[5] New Edition of College English (Second Edition). Shanghai Foreign Language Education Press, 2011. 